\title{
Disilyne with a silicon-silicon triple bond: A new entry to multiple bond chemistry*
}

\author{
Akira Sekiguchi \\ Department of Chemistry, Graduate School of Pure and Applied Sciences, \\ University of Tsukuba, Tsukuba, Ibaraki 305-8571, Japan
}

\begin{abstract}
The synthesis, crystal structure, and characterization of a silicon-silicon triply bonded species, disilyne with two bis[bis(trimethylsilyl)methyl]isopropylsilyl substituents, are described. The nature of the sp-hybridized silicon atoms is discussed from the viewpoint of spectroscopic results and theoretical calculations. The reactivity of the disilyne with alkali metals, ${ }^{t} \mathrm{BuLi}$, and $\pi$-bonded compounds such as cis- and trans-2-butenes and phenylacetylene is also described.
\end{abstract}

Keywords: aromaticity; disilabenzene; disilyne; main group 14 elements; multiple bond chemistry.

\section{INTRODUCTION}

Hydrocarbons containing $>\mathrm{C}=\mathrm{C}<$ double and $-\mathrm{C} \equiv \mathrm{C}-$ triple bonds, alkenes, and alkynes, respectively, form an abundant and structurally diverse class in organic chemistry. However, the ability of heavier congeners of carbon $(\mathrm{E}=\mathrm{Si}, \mathrm{Ge}, \mathrm{Sn}$, and $\mathrm{Pb})$ to form multiple bonds of the type $>\mathrm{E}=\mathrm{E}<$ and $-\mathrm{E}=\mathrm{E}-$ was doubted for a long time [1]. However, almost every type of doubly bonded compound having not only homo- and heteronuclear double bonds between group 14 elements of $>E=E^{\prime}<$ type $\left(E\right.$ and $E^{\prime}=C$, $\mathrm{Si}, \mathrm{Ge}, \mathrm{Sn}$, and $\mathrm{Pb}$ ), but also double bonds between the heavier group 14 elements and other main group elements (groups 13,15, and 16) have been synthesized and structurally characterized [1], since the discovery of the stable distannene $\mathrm{Dsi}_{2} \mathrm{Sn}=\mathrm{SnDsi}_{2}\left(\mathrm{Dsi}=\mathrm{CH}\left(\mathrm{SiMe}_{3}\right)_{2}\right)$ by Lappert in 1973 [2], tetramesityldisilene $\mathrm{Mes}_{2} \mathrm{Si}=\mathrm{SiMes}_{2}$ (Mes = 2,4,6-trimethylphenyl) by West in 1981 [3], and $\left(\mathrm{Me}_{3} \mathrm{Si}\right)_{2} \mathrm{Si}=\mathrm{C}\left(\mathrm{OSiMe}_{3}\right) \mathrm{Ad}(\mathrm{Ad}=1$-adamantyl) by Brook in 1981 [4]. Despite extensive experimental efforts directed toward the synthesis of triply bonded compounds of heavier group 14 elements, heavier analogs of alkynes, such as $-\mathrm{E} \equiv \mathrm{C}-$ and $-\mathrm{E} \equiv \mathrm{E}-(\mathrm{E}=\mathrm{Si}, \mathrm{Ge}, \mathrm{Sn}$, and $\mathrm{Pb})$, remained unknown until recently [5]. In 2000, Power reported the synthesis and structural characterization of the lead analog of the alkyne analogs [6], and subsequently, tin [7] and germanium [8] analogs were also synthesized by the same group in 2002 by using bulky terphenyl ligands (2,6-diarylphenyl groups) and by Tokitoh using the Bbt group $\left\{\mathrm{C}_{6} \mathrm{H}_{2}-2,6-\left[\mathrm{CH}\left(\mathrm{SiMe}_{3}\right)_{2}-4-\mathrm{C}\left(\mathrm{SiMe}_{3}\right)_{3}\right]\right\}$. However, the chemistry of disilyne with a silicon-silicon triple bond was missing until reports in 2004 by our group and Wiberg $[9,10]$. We present here the synthesis and structural characterization of a disilyne with a new type of $\pi$ bond, as well as its reactivity $[9,11]$.

\footnotetext{
*Paper based on a presentation at the $12^{\text {th }}$ International Symposium on Novel Aromatic Compounds (ISNA-12), 22-27 July 2007 , Awaji Island, Japan. Other presentations are published in this issue, pp. 411-667.
} 


\section{SYNTHESIS OF A DISILYNE}

Based on both the theoretical prediction [12] and our previous experimental study [13], we have designed the $\mathrm{Dsi}_{2}{ }^{i} \mathrm{PrSi}$ group [Dsi $=\mathrm{CH}\left(\mathrm{SiMe}_{3}\right)_{2}$ ] for the protection of a silicon-silicon triple bond. Disilyne $\mathbf{2}$ was prepared by reduction of the tetrabrominated precursor $\mathbf{1}$. Thus, the reaction of $\mathbf{1}$ with four equivalents of potassium graphite $\left(\mathrm{KC}_{8}\right)$ in tetrahydrofuran (THF) produced a dark green mixture, from which disilyne $\mathbf{2}$ was isolated as extremely air- and moisture-sensitive emerald green crystals in $73 \%$ isolated yield (Scheme 1) [9].

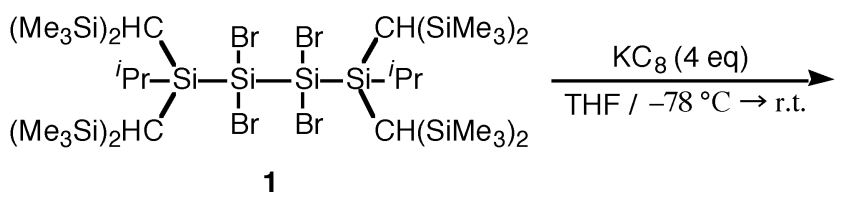

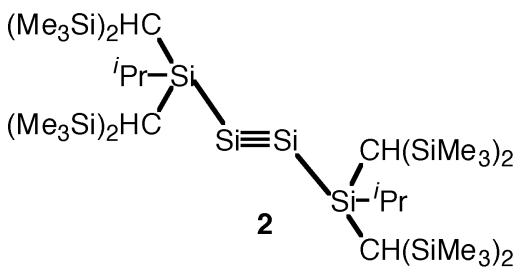

\section{Scheme 1}

Figure 1 shows the molecular structure of disilyne 2. The four $\mathrm{Si}$ atoms (Si2, Si1, Si1', and Si2') are coplanar, and the bulky $\mathrm{Si}{ }^{i} \operatorname{Pr}\left[\left(\mathrm{CH}\left(\mathrm{SiMe}_{3}\right)_{2}\right]_{2}\right.$ groups protect the central $\mathrm{Si}=\mathrm{Si}$ triple bond. The most significant result is the $\mathrm{Si}=\mathrm{Si}$ triple bond length of 2.0622(9) $\AA$. This value is $3.8 \%$ shorter than the typical $\mathrm{Si}=\mathrm{Si}$ double bond length $(2.14 \AA)$ and $13.5 \%$ shorter than the average $\mathrm{Si}-\mathrm{Si}$ single bond length of $2.34 \AA[\mathrm{g}]$. This shortening is half the magnitude of that in the carbon counterparts. Moreover, alkynes have a linear geometry around the $\mathrm{C} \equiv \mathrm{C}$ triple bond, whereas disilyne has the transbent geometry with a bending angle of $137.44(4)^{\circ}$ around the $\mathrm{Si} \equiv \mathrm{Si}$ triple bond. The structure of 2 presented here is close to that predicted by a density functional (DFT) calculation on $\left({ }^{t} \mathrm{Bu}_{3} \mathrm{Si}\right)_{2} \mathrm{MeSiSi} \equiv \mathrm{SiSiMe}\left(\mathrm{Si}^{t} \mathrm{Bu}_{3}\right)_{2}$ [14]. The space-filling model of 2 shown in Fig. 2 highlights the steric protection of the $\mathrm{Si}=\mathrm{Si}$ group by the isopropyl and bis(trimethylsilyl)methyl substituents. A DFT calculation on disilyne 2 at the B3LYP/6-31G(d) level of theory well reproduces the experimental geometry and the structural parameters (calculated value: $2.093 \AA$ for the $\mathrm{Si}=\mathrm{Si}$ bond length, $136.1^{\circ}$ for the trans-bending angle).

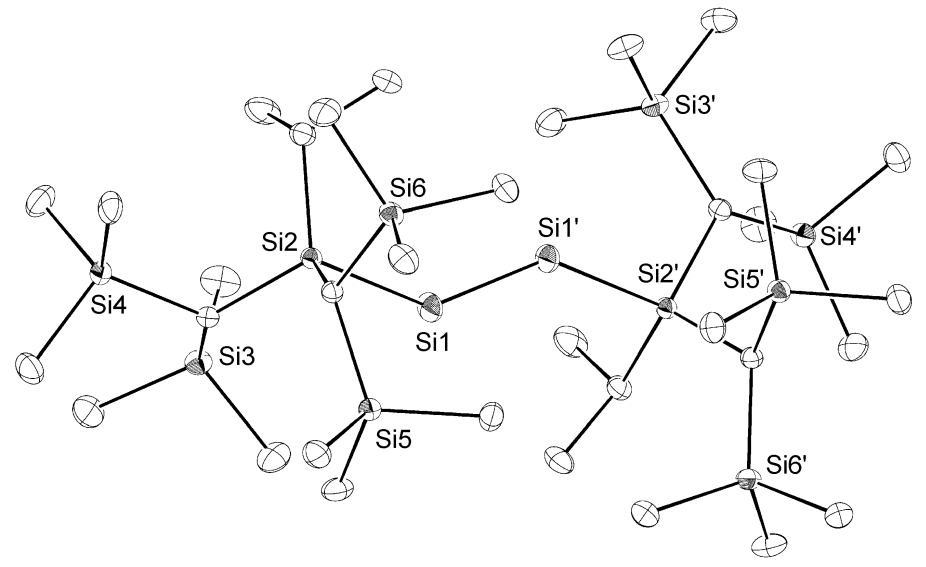

Fig. 1 ORTEP drawing of disilyne 2. 


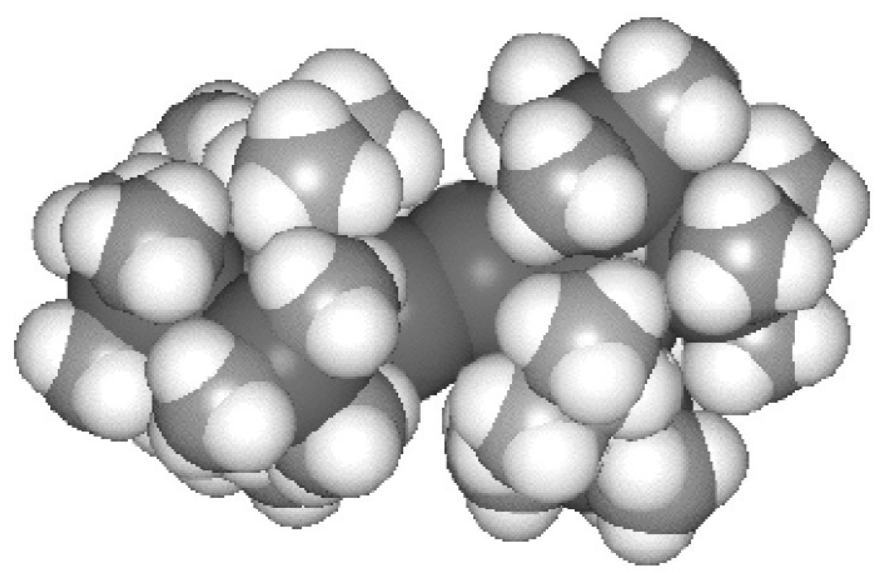

Fig. 2 Space filing model of disilyne 2.

The bending is thought to be the result of the mixing of an in-plane $\pi$ orbital with a $\sigma^{*}$ orbital whose energies are close enough to cause the interaction of these orbitals in the heavier elements (Fig. 3) [5e]. The $\sigma$ orbital of the $\mathrm{C}-\mathrm{C}$ bond cannot interact with an in-plane $\pi$ orbital because of the large energy difference, whereas the $\mathrm{Si}-\mathrm{Si} \sigma^{*}$ orbital can interact with the in-plane $\pi$ orbital to produce the trans-bent structure of $\mathrm{RSi} \equiv \mathrm{SiR}\left\{\mathrm{R}=\mathrm{Si}{ }^{i} \mathrm{Pr}\left[\mathrm{CH}\left(\mathrm{SiMe}_{3}\right)_{2}\right]_{2}\right\}$, resulting in a bond order of 2.618 [9].

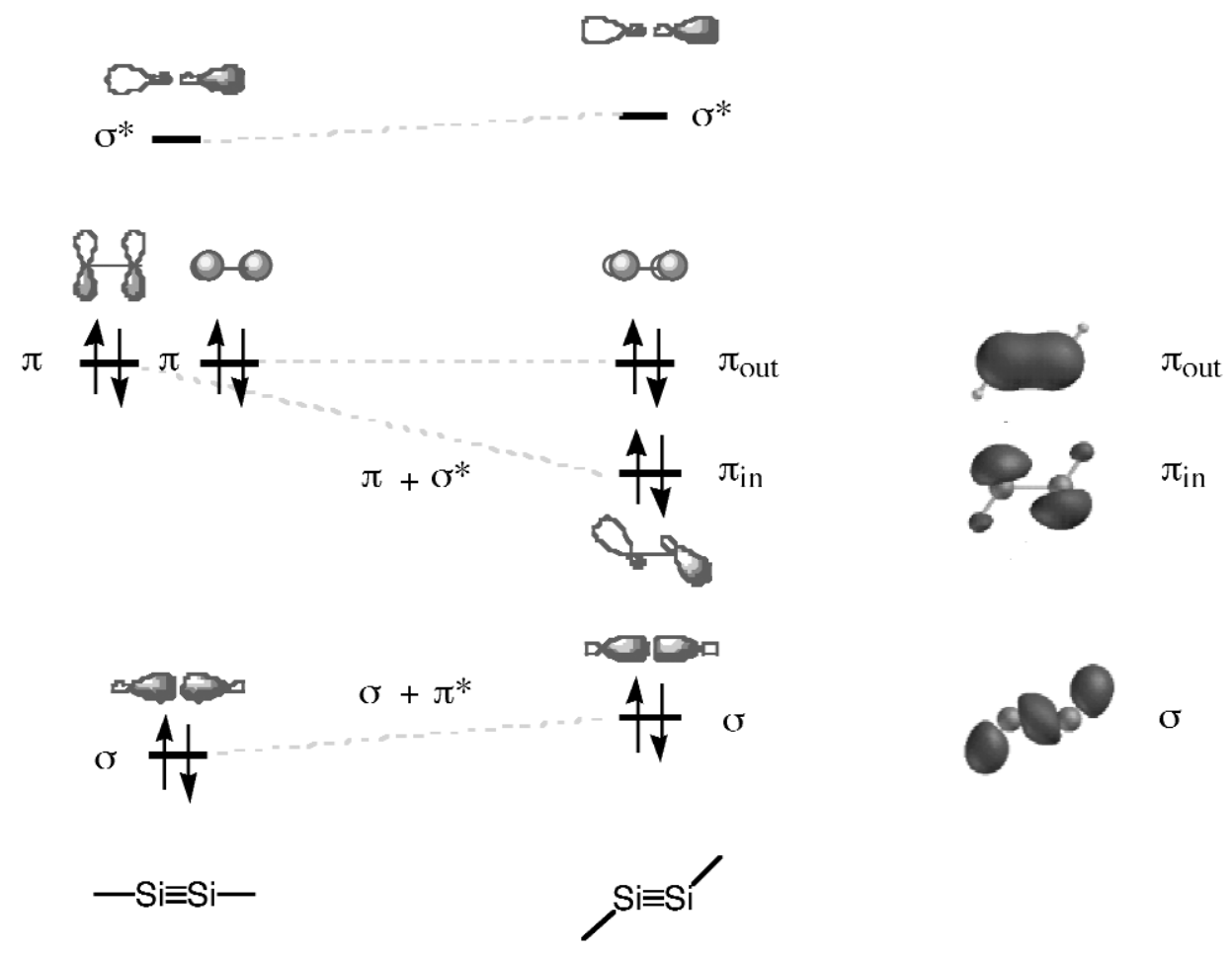

Fig. 3 Schematic MO diagrams of linear and trans-bent disilynes. 
The molecular orbitals (MOs) of disilyne 2 calculated at the HF/6-311G(d)//B3LYP/6-31G(d) level presented in Fig. 4 show two nondegenerate highest occupied $\pi$ MOs (HOMO-1 and HOMO) and two lowest unoccupied antibonding $\pi^{*}$ MOs (LUMO and LUMO+1) $[9,15]$. The out-of-plane HOMO and LUMO+1 are represented by the pure $\left(\mathrm{p}_{\mathrm{z}}-\mathrm{p}_{\mathrm{z}}\right) \pi$ MOs, whereas the in-plane HOMO-1 and LUMO are represented mainly by $\left(\mathrm{p}_{\mathrm{y}}-\mathrm{p}_{\mathrm{y}}\right) \pi$ MOs with a slight contribution from the antibonding $\sigma^{*}(\mathrm{Si}-\mathrm{Si})$ orbital of the central bond. In accordance with the triple-bond structure, a natural bond orbital analysis of 2 shows electron occupation of the two $\pi(\mathrm{Si} \equiv \mathrm{Si})$ orbitals (1.934 and 1.897 electron), indicating their bonding character. The bond order (Wiberg bond index) of Si1 $=\mathrm{Si1}$ ' is 2.618 , which agrees with the real $\mathrm{Si} \equiv \mathrm{Si}$ triple bond $[9,16]$.

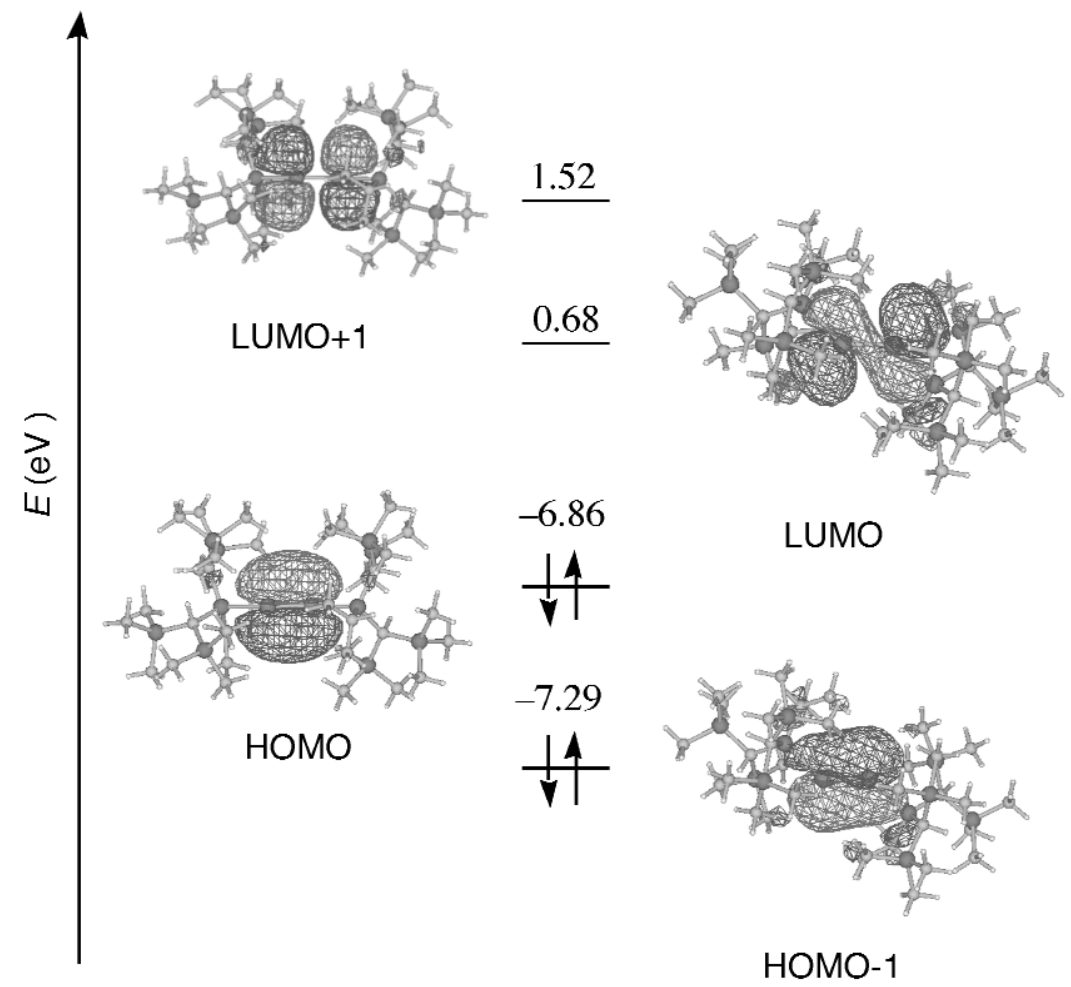

Fig. 4 Molecular orbitals of disilyne 2 calculated at the HF/6-311G(d)//B3LYP/6-31G(d) level.

\section{REACTIVITY OF A DISILYNE}

Disilyne has a characteristic structure, and the geometry around the silicon-silicon triple bond is not linear, but trans-bent, which results in splitting of the two occupied MOs $\left(\pi_{\text {in }}\right.$ for HOMO- 1 and $\pi_{\text {out }}$ for HOMO) and splitting of the two unoccupied MOs ( $\pi^{*}$ in for LUMO and $\pi^{*}$ out for LUMO+1) $[9,15]$. Upon bending, the energy of the HOMO is raised, whereas the energy of the LUMO is significantly lowered. Therefore, it is expected that disilyne $\mathbf{2}$ is prone to easy reduction of its low-lying LUMO. Indeed, the anion radical of disilyne $\mathbf{2}$ was obtained by one-electron reduction with alkali metals. Thus, the reaction of disilyne 2 with an equivalent amount of lithium, sodium, and $\mathrm{KC}_{8}$ or potassium metal in THF produced the disilyne anion radicals 3a-c (Scheme 2). In particular, the potassium salt of disilyne anion radical 3c was isolated by recrystallization from pentane and 1,2-dimethoxyethane (DME) as dark brown crystals in $63 \%$ isolated yield [17]. 


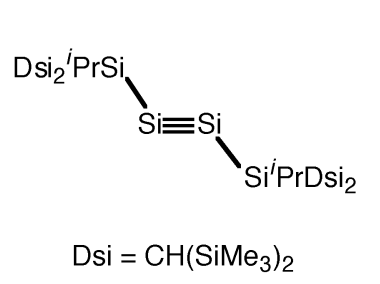

2

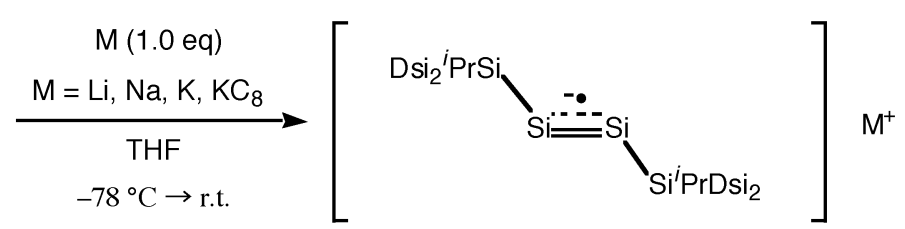

$3 a(M=L i)$

$3 b(M=N a)$ $3 c(M=K)$

\section{Scheme 2}

The electron paramagnetic resonance (EPR) spectra of 3a-c showed the same signal, indicating that $\mathbf{3 a - c}$ are metal-free disilyne anion radical species [18]. Figure 5 shows the EPR spectrum of $\mathbf{3 c}$ in 2-methyl-THF solvent. The triplet splitting of the signal arises from coupling with the two $\delta$-Hs of the isopropyl groups. The signal is accompanied by two pairs of satellite signals (3.92 and $2.24 \mathrm{mT}$ ), due to coupling of the unpaired electron with the $\alpha$ - and $\beta-{ }^{29} \mathrm{Si}$ nuclei, respectively. The magnitude of the spin coupling by the $\alpha_{-2}{ }^{29} \mathrm{Si}$ nuclei is smaller than that in the tris(di-tert-butylmethylsilyl)silyl radical (5.80 $\mathrm{mT})$ [19], implying delocalization of the unpaired electron between the central silicon atoms. The EPR spectra of 3a-c were also measured in 2-methyl-THF under glass matrix conditions (100 K). As expected, the low symmetry of the disilyne anion radicals 3a-c caused anisotropy of the $g$-factor, $g_{x x}=$ 2.00907, $g_{y y}=2.00340, g_{z z}=2.198763$.

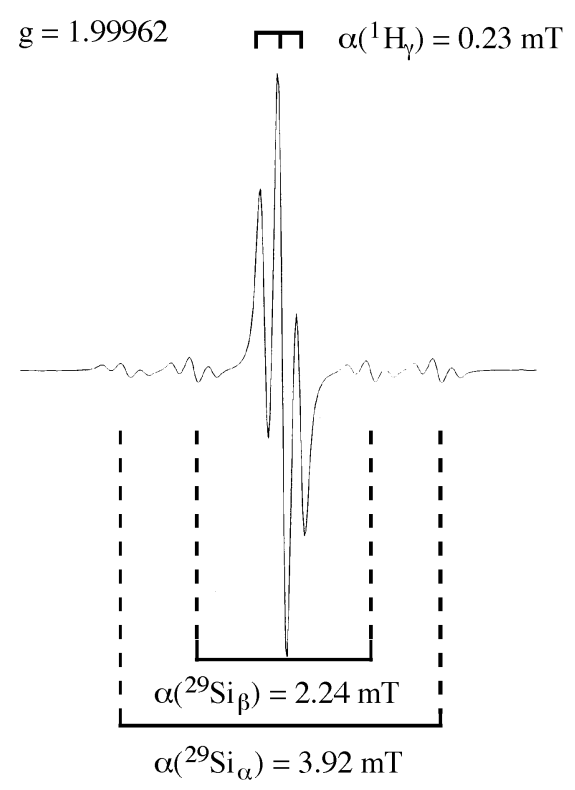

Fig. 5 The EPR spectrum of anion radical 3c in 2-Me-THF at ambient temperature.

X-ray crystallography unambiguously showed the trans-bent structure of disilyne anion radical 3c (Fig. 6) [17]. The counter cation, potassium, is solvated by four DME molecules and the distance between $\mathrm{Si} 1$ and $\mathrm{K} 1$ is greater than $11 \AA$, showing that anion radical $3 \mathbf{c}$ is free. The central $\mathrm{Si}-\mathrm{Si}$ bond length is $2.1728(14) \AA$, which is $5 \%$ longer than that of disilyne 2 [2.0622(9) $\AA$ ] [9] because of the half-occupied $\pi_{\text {in }}{ }^{*}$ orbital with antibonding character. The bond lengths of Si1-Si3 and Si2-Si4 are 


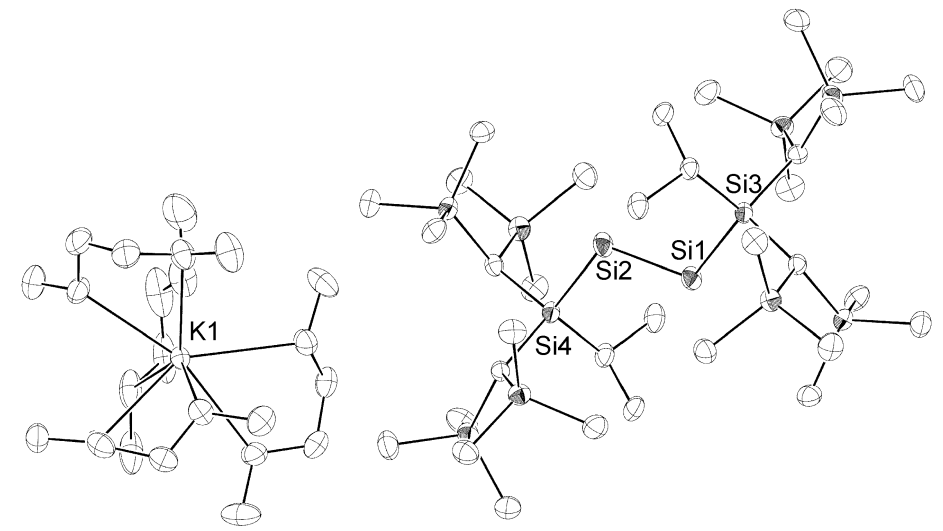

Fig. 6 ORTEP drawing of disilyne anion radical 3c.

$2.3639(13) \AA$ and 2.3714(13) $\AA$, respectively. The characteristic bond angles [112.84(6) and 113.97(6) ${ }^{\circ}$ ] of the tetrasilane unit are smaller than the corresponding bond angle $\left(137.44^{\circ}\right)$ of 2 due to the influence of the negative charge on the central silicon atoms. These bond angles are found to be essentially equal to each other, indicating delocalization of the unpaired electron between the two central silicon atoms.

The reaction of disilyne 2 with an equivalent amount of ${ }^{t} \mathrm{BuLi}$ in dry THF at $-78{ }^{\circ} \mathrm{C}$ resulted in the immediate development of a red color. Disilenyllithium 4 was isolated as air- and moisture-sensitive red crystals in $82 \%$ isolated yield (Scheme 3) [17]. The disilenide ion was also obtained as a solvent-separated ion pair 5 by the addition of DME to 4 , and purified by recrystallization from pentane, benzene, and DME at $-30{ }^{\circ} \mathrm{C}$. The present method provides an entirely new method for the preparation of disilenide derivatives by taking advantage of the reactivity of the silicon-silicon triple bond. The formation of $\mathbf{4}$ can be rationalized by assuming an initial single-electron transfer process involving intermediate formation of the anion radical of $\mathbf{3 a}$ and tert-butyl radical as a key radical pair, followed by fast hydrogen abstraction by the anion radical of $\mathbf{3}$ with the formation of disilenyllithium [20]. Therefore, disilenyllithium 4 is the product of a formal 1,2-addition of lithium hydride across the $\mathrm{Si} \equiv \mathrm{Si}$ triple bond of 2.

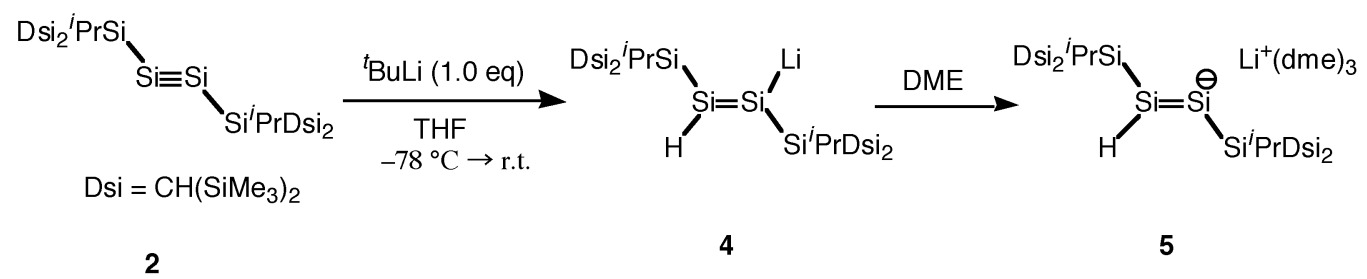

Scheme 3

\section{REACTIVITY OF A DISILYNE TOWARD THE $\pi$ BOND}

To understand the nature of the $\pi$ bond of a silicon-silicon triple bond, we have examined the reaction of disilyne $\mathbf{2}$ with alkenes and alkynes. When a hexane solution of disilyne $\mathbf{2}$ was treated with an excess of cis-2-butene at room temperature, cis-3,4-dimethyl-1,2-disilacyclobutene 6a was obtained as the sole product in $89 \%$ yield (Scheme 4) [21]. This reaction proceeded cleanly and was complete within $30 \mathrm{~min}$. On the other hand, the reaction of 2 with trans-2-butene under the same conditions produced trans-3,4-dimethyl-1,2-disilacyclobutene $\mathbf{6 b}$ as yellow crystals in $85 \%$ yield [21]. In contrast to the reaction with cis-2-butene, it took one day to complete this reaction. 


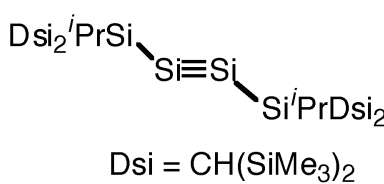

2

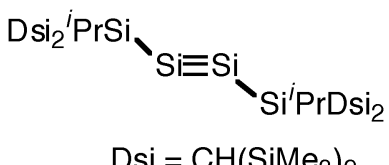

2

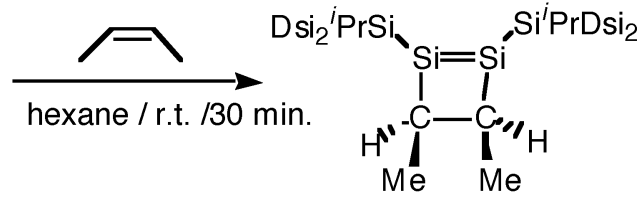

$6 a$

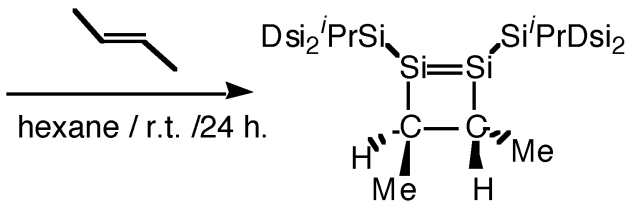

6b

\section{Scheme 4}

In order to gain a mechanistic insight, we have performed theoretical calculations of the real system on the reaction of disilyne 2 with 2-butenes. Figure 7 shows the energy profile along the reaction path calculated at the B3LYP/[Si:6-311+G(2df), C and H:6-31G(d)]//B3LYP/3-21G* level. The interaction between the in-plane LUMO $\left(\pi_{\text {in }}{ }^{*}\right)$ of 2 and the HOMO of 2-butene, resulting in a formal [1+2] cycloaddition, is the first step in both reactions to produce the silacyclopropyl-silylene intermediate (Int1). The alternative interaction between the out-of-plane HOMO $\left(\pi_{\mathrm{out}}\right)$ of $\mathbf{2}$ and the LUMO of 2-butene is unfavorable because of the larger steric repulsion between 2-butene and the $\mathrm{Si}{ }^{i} \operatorname{Pr}\left[\mathrm{CH}\left(\mathrm{SiMe}_{3}\right)_{2}\right]_{2}$ group of 2 . Because the first step is rate-determining, the reaction with trans-2butene, which has a higher energy barrier $\left(\Delta E=+23.2 \mathrm{kcal} \mathrm{mol}^{-1}\right)$, requires a longer reaction time than the reaction with cis-2-butene $\left(\Delta E=+18.4 \mathrm{kcal} \mathrm{mol}^{-1}\right)$. The difference in the heights of the energy barriers is attributed to the degree of steric repulsion between the Me group of 2-butene and the $\mathrm{Si}{ }^{i} \mathrm{Pr}\left[\mathrm{CH}\left(\mathrm{SiMe}_{3}\right)_{2}\right]_{2}$ group of 2 . Finally, the intramolecular insertion of the silylene into the neighboring $\mathrm{Si}-\mathrm{C}$ bond, followed by rotation about the $\mathrm{Si}-\mathrm{Si}$ bond with retention of the stereoconfiguration, completes the formation of products $\mathbf{6 a}, \mathbf{b}$.

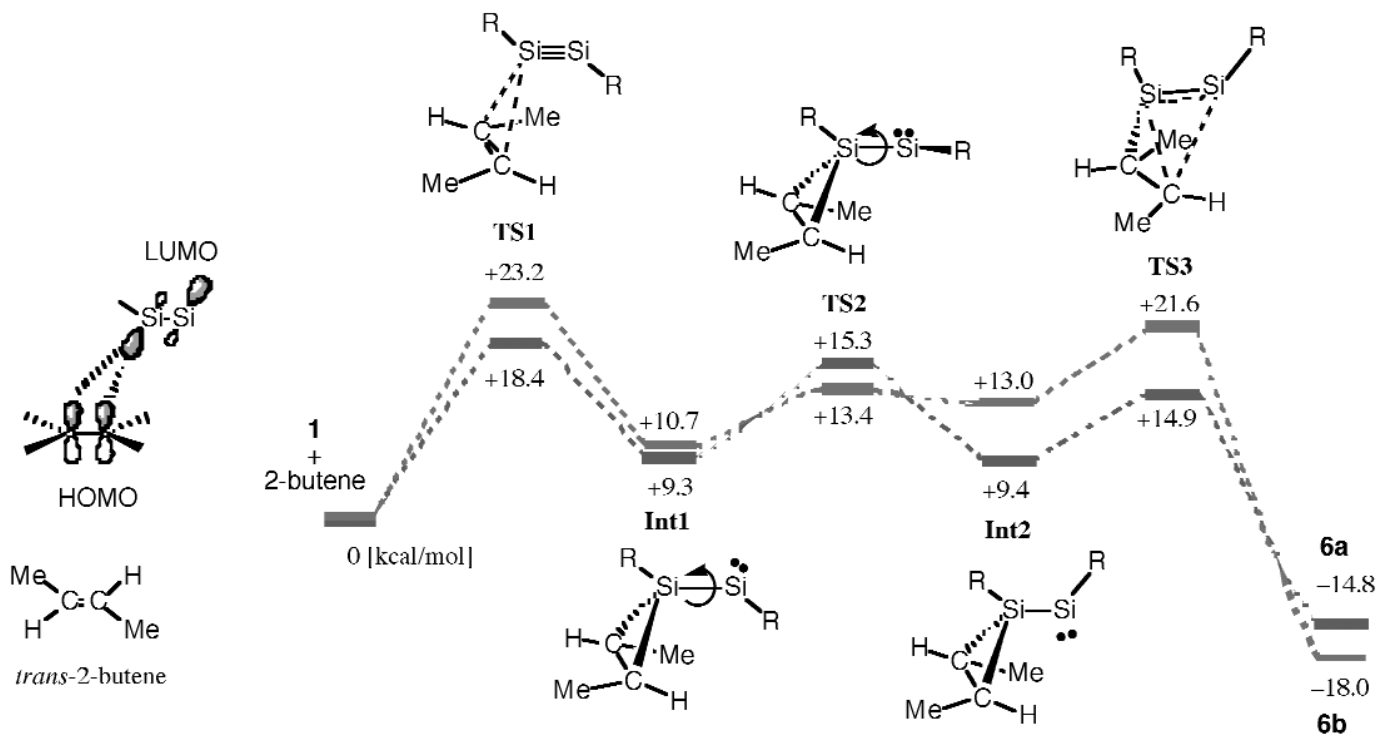

Fig. 7 Calculated energies of transition state and intermediates (kcal mol ${ }^{-1}$, B3LYP/6-31G). 
When a hexane solution of $\mathbf{2}$ was treated with an excess of phenylacetylene at room temperature, the 1,2-disilabenzene derivative $\mathbf{7}$ was obtained as a mixture of two regioisomers $(\mathbf{7 a : 7 b}=2: 3)$, isolated as yellow crystals in $63 \%$ overall yield (Scheme 5) [21]. The steric factor is important for the reaction, and no reaction occurred with diphenylacetylene. This is the first example of stable 1,2-disilabenzene derivatives, although the isolation of some stable monosilaaromatic compounds [22], as well as the chemical trapping of intermediary 1,4-disilabenzene and its observation by UV-vis spectroscopy in an Ar matrix at $10 \mathrm{~K}$ [23], have already been reported.

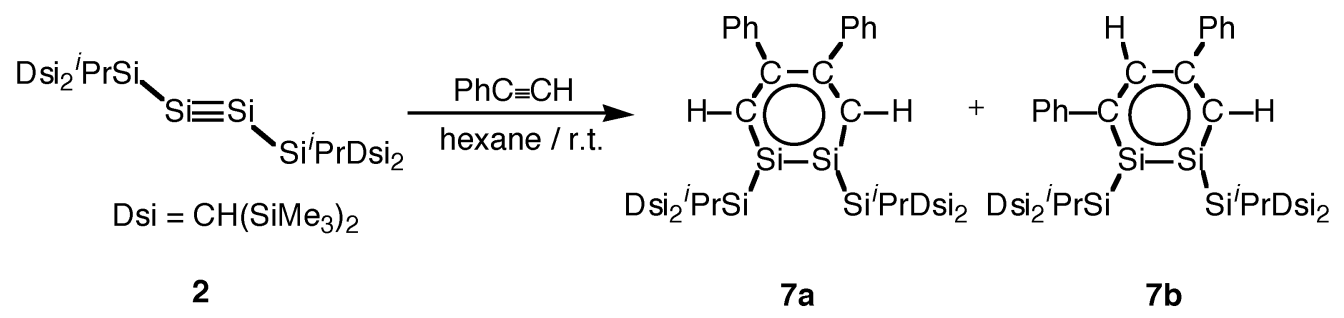

Scheme 5

The 1,2-disilabenzene ring of $\mathbf{7 a}$ is almost planar, the sum of the bond angles around the two skeletal $\mathrm{Si}$ atoms being 359.74 and $359.83^{\circ}$ for $\mathrm{Si} 1$ and $\mathrm{Si} 2$, respectively (Fig. 8). The dihedral angle between the 1,2-disilabenzene ring and each phenyl group is about $54^{\circ}$. The length of the $\mathrm{Si} 1-\mathrm{Si} 2$ bond is 2.2018(18) $\AA$, which is intermediate between the $\mathrm{Si}-\mathrm{Si}$ single- and double-bond lengths [16]. The lengths of Si1-C6 and Si2-C3 were found to be essentially equal to each other [1.804(4) and 1.799(5) $\AA$, respectively], and they are intermediate between those of $\mathrm{Si}-\mathrm{C}$ single- and double-bond lengths. Furthermore, the C3-C4 and C5-C6 bond lengths, which are also equal to each other [1.389(6) and

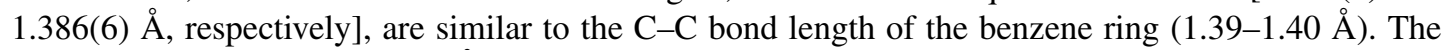
C4-C5 bond length of 1.452(6) $\AA$ is different from that of the $\mathrm{C}-\mathrm{C}$ bond length in the benzene ring, but is intermediate between those of $\mathrm{C}-\mathrm{C}$ single- and double-bond lengths (1.54 and $1.34 \AA$, respectively). Thus, it has been experimentally demonstrated that 1,2-disilabenzene has some contribution from the $6 \pi$ aromatic delocalization, similar to the cases of benzene and monosilabenzene [22,24]. Indeed, nucleus-independent chemical shift (NICS) values, recognized as an aromaticity probe, were calculated for the model compounds $\mathbf{7} \mathbf{a}^{\prime}$ and $\mathbf{7} \mathbf{b}^{\prime}\left(\mathrm{Me}_{3} \mathrm{Si}\right.$ groups instead of $\left.\mathrm{Si}^{i} \mathrm{PrDsi}_{2}\right)$ at $1 \AA$ above the center of the ring: $\operatorname{NICS}(1)=-8.0$ for $\mathbf{7} \mathbf{a}^{\prime}$ and -8.1 for $\mathbf{7} \mathbf{b}^{\prime}$ (cf. NICS(1) for benzene $=-10.6[25]$ ).
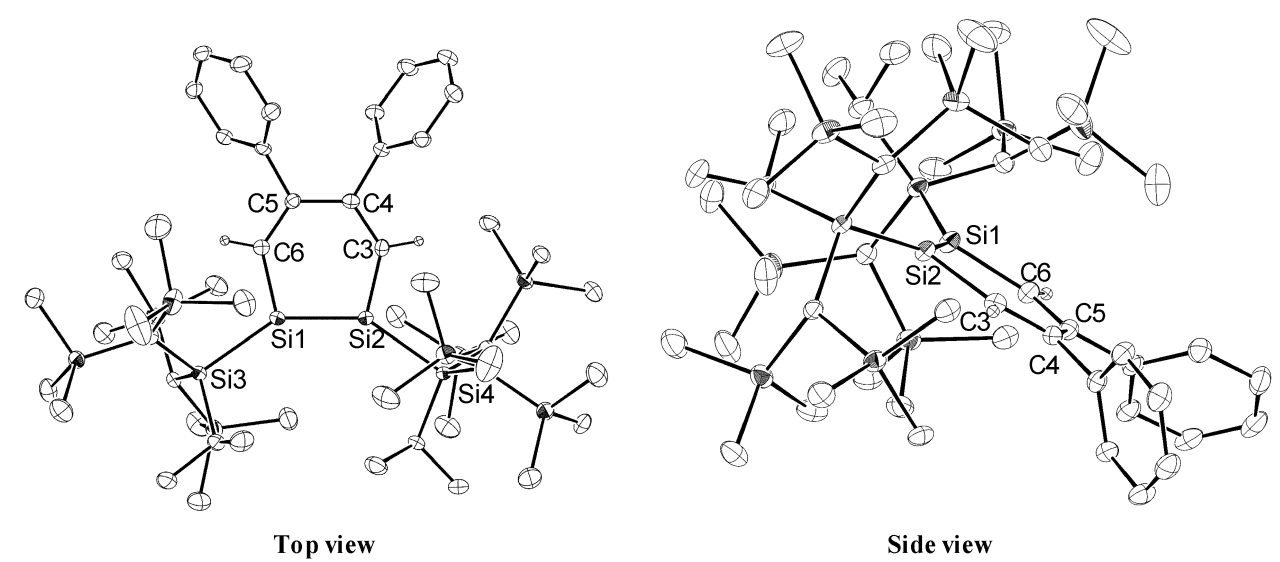

Fig. 8 ORTEP drawing of 1,2-disilabenzene 7a. 
According to the theoretical calculation, the first step in the formation of 1,2-disilabenzene is the generation of a 1,2-disilacyclobutadiene-like intermediate. Then, the [2+4] cycloaddition reaction between this intermediate and a second acetylene molecule will take place to give 1,2-disila-Dewar benzene, followed by its valence isomerization to form the final 1,2-disilabenzene [21].

The MOs of 1,2-disilabenzene 7a calculated at the HF/6-31G(d) level for X-ray data presented in Fig. 9 show two nondegenerate highest occupied $\pi$ MOs (HOMO-1 B and HOMO C) and two lowest unoccupied antibonding $\pi^{*}$ MOs (LUMO D and LUMO+1 E). These MOs correspond to those of benzene, although the energy levels are very different. The UV-vis spectrum of 7a in hexane at room temperature shows two characteristic absorption bands at 427 (116) and 382 (240) $\mathrm{nm}$ in the visible region and two broad absorption bands at 313 (745) and 246 (2548) $\mathrm{nm}$ in the ultraviolet region. As comparison, the UV-vis spectra of benzene, silabenzene, and 1,4-disilabenzene are also depicted in Fig. 10 [23b]. The absorption maxima of 1,2-disilabenzene 7a in the visible region are very similar to those of 1,4-disilabenzene $(\lambda=408,396,385,340$, and $275 \mathrm{~nm})$, observed in low-temperature matrices at $10 \mathrm{~K}$. Thus, disilabenzene derivatives showed the remarkable red-shifts as compared with those of benzene, due to the small HOMO-LUMO energy gap (Fig. 9).

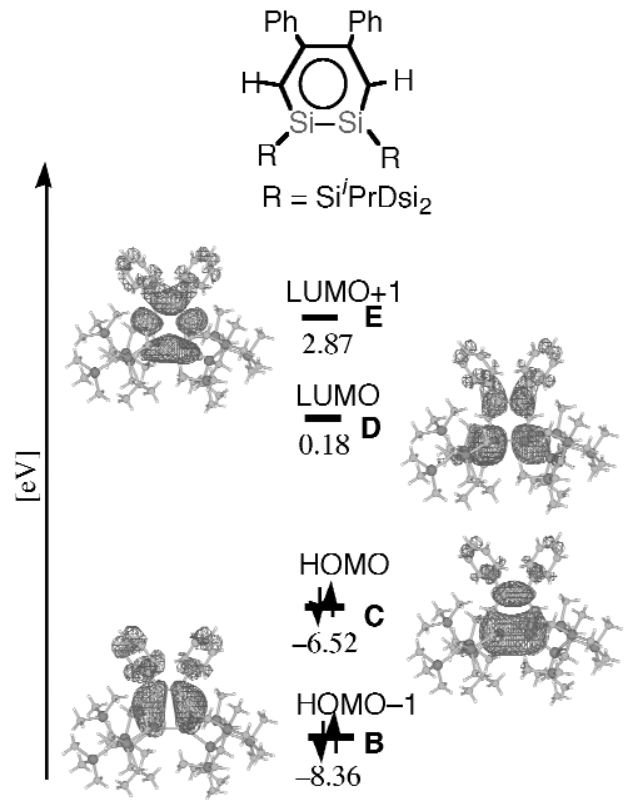

$\mathrm{HF} / 6-31 \mathrm{G}(\mathrm{d})$

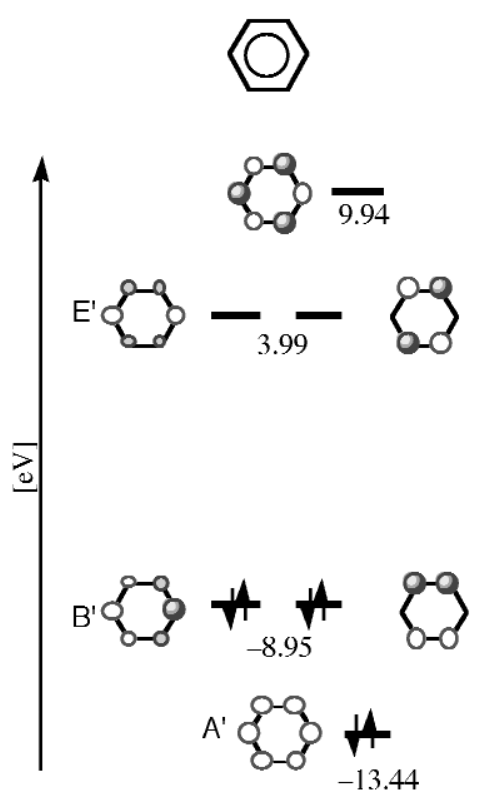

$\mathrm{HF} / 6-31 \mathrm{G}(\mathrm{d}) / / \mathrm{B} 3 \mathrm{LYP} / 6-31 \mathrm{G}(\mathrm{d})$

Fig. 9 left: MOs of 1,2-disilabenzene 7a calculated at the HF/6-31G(d)// level (X-ray data). right: Benzene at the HF/6-31G(d)//B3LYP/6-31G(d) level. 

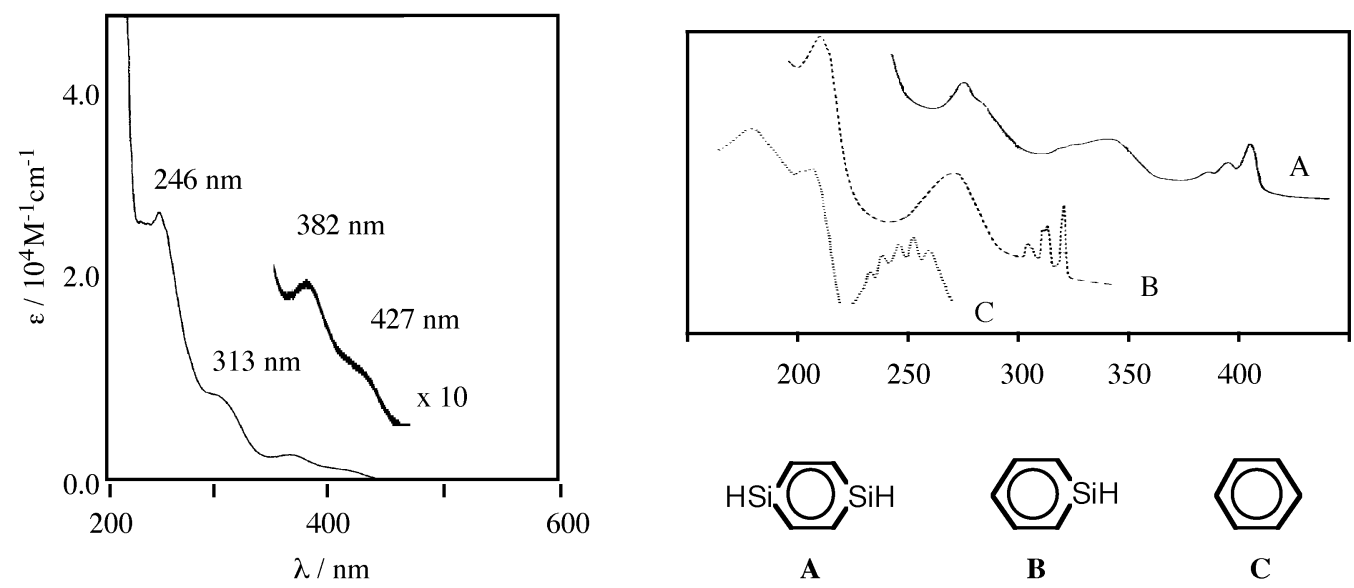

Fig. 10 left: UV-vis spectrum of 1,2-disilabenzene 7a in hexane at room temperature. right: UV-vis spectra of 1,4-disilabenzene, monosilabenzene, and benzene in Ar matrices at $10 \mathrm{~K}$.

\section{ACKNOWLEDGMENTS}

We are highly appreciative of the invaluable experimental contributions by Dr. Rei Kinjo and Dr. Masaaki Ichinohe. We wish to thank Prof. Shigeru Nagase and Dr. Nozomi Takagi for the theoretical calculations. This work was supported by a Grant-in-Aid for Scientific Research (Nos. 19105001, 19020012, 19022004, 19029006) from the Ministry of Education, Science, Sports, and Culture of Japan.

\section{REFERENCES}

1. Reviews on double bond chemistry of heavier group 14 elements: (a) P. P. Power. Chem. Rev. 99, 3463 (1999); (b) M. Weidenbruch. Eur. J. Inorg. Chem. 373 (1999); (c) J. Escudié, H. Ranaivonjatovo. Adv. Organomet. Chem. 44, 113 (1999); (d) M. Weidenbruch. The Chemistry of Organic Silicon Compounds, Vol. 3, Z. Rappoport, Y. Apeloig (Eds.), Chap. 5, John Wiley, Chichester (2001); (e) K. Klinkhammer. The Chemistry of Organic Germanium, Tin and Lead Compounds, Vol. 2, Z. Rappoport (Ed.), Part 1, Chap. 4, John Wiley, Chichester (2002); (f) N. Tokitoh, R. Okazaki. The Chemistry of Organic Germanium, Tin and Lead Compounds, Vol. 2, Z. Rappoport (Ed.), Part 1, Chap. 13, John Wiley, Chichester (2002); (g) M. Weidenbruch. Organometallics 22, 4348 (2003); (h) V. Ya. Lee, A. Sekiguchi. Organometallics 23, 2822 (2004).

2. P. J. Davidson, M. F. Lappert. J. Chem. Soc., Chem. Commun. 317 (1973).

3. R. West, M. J. Fink, J. Michl. Science 214, 1343 (1981).

4. A. G. Brook, F. Abdesaken, B. Gutekunst, G. Gutekunst, R. K. Kallury. J. Chem. Soc., Chem. Commun. 191 (1981).

5. Recent reviews on triple bond chemistry of heavier group 14 elements: (a) P. P. Power. Chem. Rev. 99, 3463 (1999); (b) M. Weidenbruch. J. Organomet. Chem. 646, 39 (2002); (c) P. P. Power. Chem. Commun. 2091 (2003); (d) M. Weidenbruch. Angew. Chem., Int. Ed. 43, 2 (2004); (e) P. P. Power. Appl. Organomet. Chem. 19, 488 (2005); (f) P. P. Power. Organometallics 26, 4362 (2007).

6. L. Pu, B. Twamley, P. P. Power. J. Am. Chem. Soc. 122, 3524 (2000).

7. M. Stender, A. D. Phillips, R. J. Wright, P. P. Power. Angew. Chem., Int. Ed. 41, 1785 (2002). 
8. (a) A. D. Phillips, R. J. Wright, M. M. Olmstead, P. P. Power. J. Am. Chem. Soc. 124, 5930 (2002); (b) Y. Sugiyama, T. Sasamori, Y. Hosoi, Y. Furukawa, N. Takagi, S. Nagase, N. Tokitoh. J. Am. Chem. Soc. 128, 1023 (2006).

9. A. Sekiguchi, R. Kinjo, M. Ichinohe. Science 305, 1755 (2004).

10. N. Wiberg, S. K. Vasisht, G. Fischer, P. Mayer. Z. Anorg. Allg. Chem. 630, 1823 (2004).

11. A. Sekiguchi, M. Ichinohe, R. Kinjo. Bull. Chem. Soc. Jpn. 79, 825 (2006).

12. (a) S. Nagase, K. Kobayashi, N. Takagi. J. Organomet. Chem. 611, 264 (2000); (b) K. Kobayashi, N. Takagi, S. Nagase. Oraganometallics 20, 234 (2001); (c) N. Takagi, S. Nagase. Chem. Lett. 966 (2001).

13. M. Ichinohe, M. Toyoshima, R. Kinjo, A. Sekiguchi. J. Am. Chem. Soc. 125, 13328 (2003).

14. N. Takagi, S. Nagase. Eur. J. Inorg. Chem. 2775 (2002).

15. A solid-state ${ }^{29} \mathrm{Si}$ NMR study of $\mathbf{2}$ also supports the presence of two different $\pi$-bonds: V. Kravchenko, R. Kinjo, A. Sekiguchi, M. Ichinohe, R. West, Y. S. Balazs, A. Schmidt, M. Karni, Y. Apeloig. J. Am. Chem. Soc. 128, 14472 (2006).

16. G. Frenking, A. Krapp, S. Nagase, N. Takagi, A. Sekiguchi. ChemPhysChem 7, 799 (2006).

17. R. Kinjo, M. Ichinohe, A. Sekiguchi, J. Am. Chem. Soc. 129, 26 (2007).

18. Anion radicals of the alkyne analogs of $\mathrm{Ge}$ and $\mathrm{Sn}$ : L. Pu, A. D. Phillips, A. F. Richards, M. Stender, R. S. Simons, M. M. Olmstead, P. P. Power. J. Am. Chem. Soc. 125, 11626 (2003).

19. (a) A. Sekiguchi, T. Fukawa, M. Nakamoto, V. Ya. Lee, M. Ichinohe. J. Am. Chem. Soc. 124, 9865 (2002); (b) V. Ya. Lee, A. Sekiguchi. Eur. J. Inorg. Chem. 1209 (2005).

20. Disilenides: (a) D. Scheschkewitz. Angew. Chem., Int. Ed. 43, 2965 (2004); (b) M. Ichinohe, K. Sanuki, S. Inoue, A. Sekiguchi. Organometallics 23, 3088 (2004); (c) S. Inoue, M. Ichinohe, A. Sekiguchi. Chem. Lett. 34, 1564 (2005).

21. R. Kinjo, M. Ichinohe, A. Sekiguchi, N. Takagi, M. Sumimoto, S. Nagase. J. Am. Chem. Soc. 129, 7766 (2007).

22. For recent reviews on stable silaaromatic compounds: (a) N. Tokitoh. Acc. Chem. Res. 37, 86 (2004); (b) N. Tokitoh. Bull. Chem. Soc. Jpn. 77, 429 (2004); (c) V. Ya. Lee, A. Sekiguchi. Angew. Chem., Int. Ed. 46, 6596 (2007).

23. (a) J. D. Rich, R. West. J. Am. Chem. Soc. 104, 6884 (1982); (b) G. Maier, K. Schöttler, H. P. Reisenauer. Tetrahedron Lett. 26, 4039 (1985); (c) Y. Kabe, K. Ohkubo, H. Ishikawa, W. Ando. J. Am. Chem. Soc. 122, 3775 (2000).

24. (a) K. Wakita, N. Tokitoh, R. Okazaki, S. Nagase. Angew. Chem., Int. Ed. 39, 634 (2000); (b) K. Wakita, N. Tokitoh, R. Okazaki, N. Takagi, S. Nagase. J. Am. Chem. Soc. 122, 5648 (2000).

25. P. v. R. Schleyer, M. Manoharan, Z.-X. Wang, B. Kiran, H. Jiao, R. Puchta, N. J. R. v. E. Hommes. Org. Lett. 3, 2465 (2001). 